\title{
Toward a Comprehensive Model for Nahuatl Language Research and Revitalization
}

\author{
JUSTYNA OLKO, ${ }^{\mathrm{a}} \mathrm{JOHN}_{\text {SULLIVAN }}^{\mathrm{a}, \mathrm{b}, \mathrm{c}}$ \\ University of Warsaw; $;^{a}$ Instituto de Docencia e Investigación Etnológica de Zacatecas ${ }^{b}$ \\ Universidad Autonóma de Zacatecas ${ }^{c}$
}

\section{Introduction}

Nahuatl, a Uto-Aztecan language, enjoyed great political and cultural importance in the pre-Hispanic and colonial world over a long stretch of time and has survived to the present day. ${ }^{1}$ With an estimated 1.376 million speakers currently inhabiting several regions of Mexico, ${ }^{2}$ it would not seem to be in danger of extinction, but in fact it is. Formerly the language of the Aztec empire and a lingua franca across Mesoamerica, after the Spanish conquest Nahuatl thrived in the new colonial contexts and was widely used for administrative and religious purposes across New Spain, including areas where other native languages prevailed. Although the colonial language policy and prolonged Hispanicization are often blamed today as the main cause of language shift and the gradual displacement of Nahuatl, legal steps reinforced its importance in Spanish Mesoamerica; these include the decision by the king Philip II in 1570 to make Nahuatl the linguistic medium for religious conversion and for the training of ecclesiastics working with the native people in different regions. Members of the nobility belonging to other ethnic groups, as well as numerous non-elite figures of different backgrounds, including Spaniards, and especially friars and priests, used spoken and written Nahuatl to facilitate communication in different aspects of colonial life and religious instruction (Yannanakis 2012:669-670; Nesvig 2012:739-758; Schwaller 2012:678-687).

Rapid changes and profound threats appeared after the Mexican War of Independence in 1821, when the Spanish infrastructure which used Nahuatl alphabetic writing as an official medium for documentation and communication, especially at the level of local municipalities, disappeared. Integrating indigenous communities into national life was not among the aims of a new succession of governments, and Nahua communities became more and more isolated not only from each other, but also from the rest of Mexican society. Indigenous writing was no longer employed for legal purposes and for recording historical tradition within communities, and differences between regional linguistic variants increased. The foundation for present day Mexico's adverse language ideology was established after the Mexican Revolution, when

\footnotetext{
1 Interlineal glossing abbreviation used in this article include ABS.SG (singular absolutive suffix), NPRES (non-present verbal suffix), OBJ.1SG (first person singular specific object prefix), OBJ.1PL (first person plural specific object prefix), OBJ.3SG (third person singular specific object prefix), POSS (possessive suffix), POSS.1SG (singular possessive prefix), SBJ.2SG (second person singular subject prefix), SBJ.3SG (third person singular subject prefix), and SG (singular subject suffix).

2 According to the Instituto Nacional de Estadística y Geografía (Mexican National Institute of Statistics and Geography).

http://www.inegi.org.mx/prod_serv/contenidos/espanol/bvinegi/productos/censos/poblacion/poblacion_indigena/len g_indi/PHLI.pdf
} 
intellectual elites engaged in the creation of a new national identity. Although it was based in part on pride in a mythologized version of Mexico's indigenous past, modern native groups, considered an obstacle to the modernization and progress of society as a whole, needed to be fully Hispanicized. Thus, today's Mexican multilingualism can be characterized as a conflictive, substitutive, and diglossic bilingualism, in which the coexistence of different languages is considered a historical stage leading to a new monolingualism (Flores Farfán 2002:228). A widespread attitude of racism, along with an accelerating, discriminatory educational and mass media policy of Hispanicization has drastically slowed or virtually eliminated the intergenerational transfer of the language in Nahua communities. The pervasive ideology shared by indigenous and non-indigenous people alike considers native languages a chaotic amalgamation of mutually incomprehensible "dialects," degenerated and impoverished under the sustained influence of Spanish, and thus not deserving the status of a language such as Spanish and English. Modern Nahua communities suffer both from what has been defined as a social dislocation originating in the lack of prestige and power, and from a closely related cultural dislocation, resulting from modernization and globalization (Grenoble 2011:34). Urbanization speeds up these processes, while the increasing use of Spanish, the national language in all domains of life, as well as massive migration to larger towns and to the United States, contribute to an ongoing disruption of language transmission.

\section{The current status of Nahuatl}

The negative language ideology which is shared by Nahuatl speakers themselves, other members of their communities, and the larger society, and sustained to a certain degree by academics, is based on several major assumptions. One is a belief in the degenerative impact of Spanish which leads to an inevitable reduction in language complexity and integrity, resulting today in "mixed dialects." Another assumption is that the restriction of the use of language to the household and agricultural domains is responsible for an alleged disappearance of vocabulary linked to other spheres of life, including socio-political and ritual contexts. Indeed, from the first decades of contact, Nahuatl and other native languages began to evolve in response to the strong and long-term impact of Spanish, a process that continues today. However, our research shows that in spite of this heavy impact and the steadily growing number of bilinguals today in native communities, local variants of the language maintain a strong continuity with colonial Nahuatl. This fact is often denied in mainstream and popular ideology. By the same token, continuity is not sufficiently addressed and emphasized in existing scholarship and, as a result, views of modern Nahuatl in academic research have contributed to the current depreciated status of the language and its speakers. The artificial notion of "Classical Nahuatl" has long been considered the only correct and original form of the language, while modern "dialects" are often still seen as its corrupted, Spanish-influenced offspring. It is perhaps for this reason that Nahuatl dialectology has attracted relatively little attention among scholars (Canger 1988:29). 


\subsection{Contact-induced language change}

The pioneering research on Nahuatl in post-conquest times was done by Karttunen and Lockhart (1976), who postulated three phases of adjustment to Spanish. Lockhart (1992) further proposed a fourth, partly overlapping stage, characterized by the development of a heavily Nahuatlized version of Spanish. Four general stages along with associated typological changes were also proposed by Jensen (2008). Studies of modern Nahuatl mostly deal with heavily Hispanized varieties and specific cases of language displacement (Canger 2001; Flores Farfán 1999, 2008; Hill and Hill 1986). However, there have been no systematic attempts to relate colonial, contact-induced changes to the structural diversity of modern varieties in terms of similarity to older Nahuatl and degrees of Hispanization as well as the role of historical, social, and cultural factors.

In Stage 1, extending from the arrival of the Spaniards to ca. 1540-1550, Nahuatl remained largely unaffected, though our most recent research based on the earliest documents identified so far and dating to the 1540s, reveals the incorporation of loanwords and even lexical calques. In Stage 2, dating approximately from the mid-sixteenth to the mid-seventeenth century, Nahuatl is characterized by the widespread borrowing of Spanish nouns undergoing phonological and morphological adaptations, loanblends combining morphemes of different origin, extensions of meaning of native vocabulary as well as borrowed verbs, which were treated as nouns by the speakers of Nahuatl. In Stage 3, which begins in the mid-seventeenth century and continues to the present, many simultaneous changes have taken place, including the borrowing of verbs and particles, the adoption of plural forms and phonemes absent in earlier Nahuatl, and the creation of lexical and lexico-syntactic calques. A fourth, partly overlapping stage, is characterized by interference through shift, resulting in a heavily Nahuatlized version of Spanish (Lockhart 1991:105-121; Melton-Villanueva 2012), which in turn contributed to the development of modern Mexican Spanish.

A systematic analysis of language data associated with the colonial period reveals a parallel, prolonged use of neologisms beyond Stages 1 and 2, often produced by combining existing words or by novel uses of affixes. The process of coining neologisms continued well beyond the first stage of contact into times when noun borrowing became widespread; moreover, it is also a common phenomenon in present varieties of Nahuatl. Lexical borrowing in the first two centuries of interaction mainly involved the introduction of terms and concepts which were absent in Nahuatl; today, older terminology is often replaced by its Spanish equivalents as meanings and contexts of use have changed. However, phonological and morphological adaptations occurring today are not much different from those attested throughout the colonial period, including the application of inflectional and derivational morphology.

Loanblends have been in use from the sixteenth century, including noun compounding (1-2), incorporation (3-4), and the creation of abstract/collective nouns (5): 
(1) cabildotlacatl 'a municipal officer' (lit. 'a town councilman')

(2) zoquicandelero 'a clay candleholder'

(3) cahuayotlatlalochtia 'to run horses'

(4) gobernadortlalia 'to be installed as governor'

(5) tenienteyotl 'the office of a deputy' or 'deputyship' (from teniente 'deputy')

Less common are imported affixes added to native stems, usually pointing to a more complex and sustained interaction between the two languages: for example, the Spanish word chocolatera 'a chocolate vendor', created initially from the Nahuatl xocolatl and the Spanish suffix -era, is attested in Nahuatl around 1650.

Lexical calques had entered the language in the sixteenth century, whereas lexico-syntactic calques are attested in the seventeenth century and continue to be a very productive mechanism today. Words appear in new syntactic contexts, including Spanish-influenced word order and new constructions:

(6) piya 'to own something' (originally 'to keep or have custody of something'; after Sp. tener)

(7) quipiya para... 'to have to [do something]' (after Sp. tener que)

(8) casado ica 'to be married to...' (after Sp. casado con)

We also deal with the innovative use of prepositions in prepositional phrases that correspond to the prepositions and syntactic structure of the source language:

(9) pan Tepecxitlan 'to/at Tepecxitlan'

(10) Niyaz huanya ta "'I'll go with you'

Changes of grammatical categories are also attested:

(11) Ninotoca Juan 'My name is Juan' (lit. from Sp. Me llamo Juan)

In the last example, toca, originally a noun, tocaitl, became a reflexive verb corresponding to the Spanish llamarse. Also, a pragmatically marked word order in the target language becomes unmarked by reproducing the corresponding neutral word order in the source language, as in (12):

(12) Niyaz mohuanya 'I will go with you', used instead of mohuanya niyaz 'with you I will go'

It is common for relational words to gradually lose their possessors, as in (13):

(13) pan cuamezah 'on the table' (instead of the more traditional ipan cuamezah) 
Among common changes are the pluralization of inanimate nouns (although modern variants of Nahuatl did not completely replace the traditional form of pluralization limited to animate objects), or the new roles of an interrogative pronoun tle/tlen/tlein acquiring the functions of the Spanish subordinator que, and preposition de. A person's speech, which has been traditionally reported in a direct manner (14), is now expressed through indirect speech (15):

(14) Niquillih noconeuh, 'Xiyauh tianquizco' 'I told my child, "Go to the market",

(15) Niquillih noconeuh ma yohui tianquizco or Niquillih noconeuh para yohui tianquizco 'I told my child to go to the market'

Thus, prolonged contact over several centuries resulted in simultaneous lexical, morphological, phonological, and syntactic adaptations that show clear patterns through the colonial period and continue to the present. Many of these phenomena, probably spurred by a growing presence of bilingual speakers, are typical of Stage 3 and originate in the middle and late colonial times. They extend in significant ways to modern variants of Nahuatl, where transformations in morphology and syntax under the influence of Spanish are obviously more widespread and profound than in late colonial sources, even if many contact-induced changes clearly follow patterns of transformation established already during much earlier stages of interaction. It is also becoming more and more clear in our research that language change in specific localities depended not only on the degree of contact and urbanization, but also on more subtle cultural factors, e.g., the strength of local indigenous organization and the continuity of the writing tradition in Nahuatl, which accounts for a relatively late occurrence of specific phenomena in areas of intense contact such as the Valley of Mexico and the Puebla-Tlaxcala region.

\subsection{Continuity between older and modern Nahuatl}

Today, both in more heavily urbanized zones, such as Tlaxcala and Puebla, and peripheral locations, such as northern Veracruz, close correspondences with earlier stages of language development are patent. They are easily recognizable in the lexicon in the massive survival of traditional terminology, as well as on the level of morphology, syntax, and phonology.

For example, the forms of the nominal possessive suffixes and the preterite are at an earlier stage of evolution in today's Eastern Huastecan variant than they were almost five hundred years ago in Central Mexico upon the arrival of the Spaniards. Possession of nouns is achieved in Nahuatl by the combination of eight possessive prefixes (first through third persons, singular and plural, as well as a human and a non-human non-specific prefix) and a set of possessive suffixes, which originated long before the Conquest as -hua [-wa:], followed by subject number markers of $-\varnothing$ for singular and $-n\left[-n_{0}\right]$ for plural. Over the last five hundred years and in all variants, plural possessed animate nouns have continued to end in -huan [-wa:n]. Through the process of 
vowel raising, the word-final singular form, -hua [-wa], ${ }^{3}$ first became -hue [-we], and by the early sixteenth century had further progressed to -hui [-wi] after a few noun roots ending in a consonant, and -uh [-M] or [-h] after a larger number of roots ending in a vowel. However, in the majority of cases singular possessed nouns ended in $-\varnothing$, because the possessive suffix had disappeared altogether. This is largely the case in all varieties today; however, peripheral varieties tend to have a larger proportion of singular possessed nouns ending in -hui [-wi] and uh $[-M]$ or $[-h]$. The following are two examples of how the process of vowel raising and loss had progressed further almost five hundred years ago in Central Mexican Nahuatl than it has today in Modern Huastecan Nahuatl:

\section{Classical Nahuatl (mid-sixteenth century) Modern Huastecan Nahuatl}

nopah /nopah/

nopahhui /nopahwi/

$\varnothing$-no-pah-[Ø]-Ø

Ø-no-pah-hui-Ø

SBJ.3SG-POSS.1SG-medicine-[POSS]-SG

SBJ.3SG-POSS.1SG-medicine-POSS-SG

'It is my medicine.'

'It is my medicine.'

ixochi /ifo:t $\mathrm{j} \mathrm{i} /$

ixochiuh /ijo:tjih/

Ø-i-xochi-[Ø]-Ø

$\varnothing$-i-xochi-uh-Ø

SBJ.3SG-POSS.3SG-flower-[POSS]-SG

SBJ.3SG-POSS.3SG-flower-POSS-SG

'It is her flower.'

'It is her flower.'

The archaic character of the preterite in Modern Huastecan Nahuatl is equally if not more interesting. At the time of the arrival of the Spaniards, the preterite in Central Mexican Nahuatl was achieved through two processes. In the first process, verb roots had been undergoing final vowel reduction, and by the early sixteenth century there were four regular verb classes: three with reduced roots and one unreduced. In the second process, a suffix, the purpose of which perhaps was to identify tenses other than the present, ${ }^{4}$ was added to the verb root. The earliest form of this suffix was -ca [-ka:], and in the same way as the possessive suffix described above, it underwent vowel raising in unprotected word final environments. Then as today in all

\footnotetext{
$3 \quad$ Long vowels are shortened in word final position.

4 Different forms of this suffix are employed in the construction of the preterite, pluperfect, and future tenses, as well as the optative mode.
} 
varieties, the plural of preterite verbs is -queh $[-\mathrm{keh}] .{ }^{5}$ But in early sixteenth-century Central Nahuatl the suffix had been completely eliminated in all singular forms except for Class 1 verbs. In this case, the unreduced root final vowel permitted -ca to be reduced completely to -c [-k], and it has remained so in all modern varieties. The following is a Class 1 verb conjugated in the preterite with a singular subject, illustrating the reduction of the non-present suffix to -c. The example could be taken from a colonial manuscript or from everyday speech in any modern variety of Nahuatl.

\section{All temporal and regional variants}

CLASS 1

titechittac/titetfitak/

ti-tech-itta-c- $\varnothing$

\section{SBJ.2SG-OBJ.1PL-see-NPRES-SG}

'You saw us.'

Modern Huastecan Nahuatl, on the other hand, has preserved a singular form of the suffix as -qui [-ki] in Classes 2 and 4. The same suffix is also attested in colonial-period documents from Tlaxcala in Central Mexico. The following examples illustrate again how the process of vowel raising and loss, this time in the case of the non-present suffix associated with the preterite, had progressed further almost five hundred years ago in Central Mexican Nahuatl than it has today in Modern Huastecan Nahuatl.

Classical Nahuatl (mid-sixteenth century) Modern Huastecan Nahuatl CLASS 2

ticcouh /tikkoh/_ticcouhqui /tihkohki/

ti-c-couh-[Ø]-Ø ti-c-couh-qui- $\varnothing$

SBJ.2SG-OBJ.3SG-buy-[NPRES]-SG SBJ.2SG-OBJ.3SG-buy-NPRES-SG

'You bought it.' 'You bought it.'

CLASS 4

5 The original suffix $-c a$ has been reduced to -que, followed by the plural suffix $-h$. 

nechcuah /net $\int \mathrm{k}^{\mathrm{w}} \mathrm{ah} /$
nechcuahqui /net $\int \mathrm{k}^{\mathrm{w}}$ ahki/
Ø-nech-cuah-[Ø]-Ø
$\varnothing$-nech-cuah-qui-Ø
SBJ.3SG-OBJ.1SG-bite-[NPRES]-SG
SBJ.3SG-OBJ.1SG-bite-NPRES-SG
'It bit me.'
'It bit me.'

And what is particularly fascinating is that Class 3 verbs in this variant are in a state of transition between employment and elimination of the suffix, so its use is optional.

Classical Nahuatl (mid sixteenth century)
quicelih /kiselih/
Ø-qui-celih-[Ø]-Ø
SBJ.3SG-OBJ3SG-receive-[NPRES]-SG

'She received it.'

\author{
Modern Huastecan Nahuatl \\ CLASS 3 \\ quicelih /kiselih/ \\ Ø-qui-celih-[Ø]-Ø
}

SBJ.3SG-OBJ3SG-receive-NPRES-SG

'She received it.'

or

quicelihqui /kiselihki/

$\varnothing$-qui-celih-qui- $\varnothing$

SBJ.3SG-OBJ3SG-receive-NPRES-SG

'She received it.'

It should be clear that the variants of Nahuatl have not evolved in a linear, monolithic fashion. However, as a whole they have developed and continue to develop, albeit at different rates, according to parameters established by the language's inherent structure, one aspect of which is the process of vowel raising and loss. Contact with Spanish should not be considered a negative factor leading to the deterioration and impoverishment of Nahuatl; rather it should be viewed as a complex case of cross-cultural contact, providing the indigenous language, through the incorporation of vocabulary and grammatical structures, with new communicative possibilities. It did not provoke a rupture in the internal, continuous evolution of the varieties of Nahuatl. Both of these facts should constitute important arguments in constructing positive language attitudes today.

\subsection{Levels and factors of endangerment}


The available classifications and assessments regarding the level of endangerment of Nahuatl are too optimistic, and reliable data are lacking. For example, the Ethnologue's (Lewis et al. 2014) classifications need updating and verification because they do not reflect the sudden decrease in language use that has occurred within the last two decades. Thus modern varieties of Nahuatl are classified between "developing" (level 5), assuming that the language is "in vigorous use" and there is a standardized form of literature used by some of the speakers, through "vigorous" level 6a, implying that it is used by all generations and in face-to-face communication, and "threatened" level $6 \mathrm{~b}$, referring to a dwindling number of native speakers, even if they belong to all generations. Only a few communities in the State of Mexico and in Guerrero are classified as "shifting" level 7, which means that there are middle-aged adults still using the language, but intergenerational transmission is lacking. In fact, only this level of endangerment (level 7) corresponds to the current situation of numerous Nahuatl-speaking communities across Mexico, where the speaker base is constantly shrinking.

Except for a limited number of communities, where intergenerational transmission is intact but subject to widespread bilingualism and an entirely Spanish school system ${ }^{6}$, the large number of passive speakers in the generations under 40-50 years old threatens to totally disrupt language transmission. This situation prevails today in the Nahua world. Accordingly, depending on a specific community where Nahuatl is still spoken, the status of the language should be described either as 'disappearing' (Grenoble and Whaley 2006:18), that is, showing a strong shift towards Spanish and an overall decrease in the proportion of intergenerational transfer; 'moribund', with no transmission to children; or 'nearly extinct,' with only a few speakers of the oldest generation remaining. In fact, many members of native communities can be classified as "ghost speakers" (Grinevald and Bert 2011:51), who conspicuously deny any knowledge of Nahuatl in spite of evidence that they do have some level of competence. This happens both inside the community space and in the eyes of outsiders, attesting to negative attitudes toward the language and the refusal of community members to identify themselves as speakers of Nahuatl.

The single most crucial factor contributing to language loss is the decrease or disruption in intergenerational language transmission inside Nahua communities. This widespread phenomenon is strengthened by a lack of adequate educational support and adverse language ideology. Another essential factor contributing to increasing endangerment is the fact that materials for language education and literacy are scarce or non-existing. There is no widely accessible or commonly used literature in Nahuatl today. Likewise, no monolingual reference materials exist and written resources are limited to textbooks for the basic level school system. This situation becomes even more problematic due to the lack of consensus regarding standardized orthography. To make things even worse, it should be borne in mind that instruction in Nahuatl and its teaching materials form part of a school system geared toward an overall shift to Spanish. Different sources of pressure, including all forms of discrimination and negative ideology have caused parents to cease speaking their native language, and thus destabilize the

6 For example, San Miguel Canoa and San Isidro de Buensuceso; Santa María Zoyatla in the municipality of Tepeojuma, all in the state of Puebla. 
linguistic environment at home. And in those communities where the youngest speakers are middle-aged or belong to the generation of grandparents, parents cannot teach the language to their children. In addition, as a consequence of patterns established already in the nineteenth century, more and more Nahua communities today are becoming reduced islands of speakers, with different degrees of transmission.

It is clear that all essential criteria of endangerment (Brenzinger 2007:ix) are met by today's varieties of the language: the low percentage and proportion of speakers within a population, the varying and quickly diminishing extent of language transmission, the loss of functions in language use and its failure to expand to new domains of modern life and media, as well as the profusion of adverse language attitudes, strengthened by tendencies in scholarly research and education that fail to recognize essential continuities between older and modern Nahua language and culture.

\subsection{Educational challenges}

In 2003 a federal law was created in order to protect the linguistic rights of Mexican indigenous people; simultaneously, federal education legislation was modified, guaranteeing, at least in theory, access to basic education in indigenous languages. ${ }^{7}$ At the same time, the National Institute of Indigenous Languages (INALI) was founded as a state institution charged with overseeing the implementation of the law, within a context of national governmental decentralization. Its primary function was to promote and coordinate the establishment of indigenous language institutes as well as legislation, and most importantly, statutes providing means of enforcement of this legislation at the level of the individual states. ${ }^{8}$ However, there are still serious impediments to the implementation and execution of laws relating to linguistic rights, given that the perpetuation of colonial attitudes is common among law-makers (Zimmermann 2011:22-23). In addition, INALI has not undertaken or sponsored concrete programs of massive language revitalization and it has been silent in regard to many key issues, thus contributing to the ongoing discrimination of indigenous languages. For example, the prevailing majority of native people still do not have access to basic education in their native tongue, whereas the implementation of national standardized testing (ENLACE ${ }^{9}$ and EXANI/EGEL ${ }^{10}$ ) clearly discriminates against non-native speakers of Spanish.

In 1964 the first generation of bilingual educators was recruited by the federal Secretary of Public Education for the purpose of assuring that indigenous school children gain literacy in

$7 \quad$ Ley general de derechos lingüísticos de los pueblos indígenas (http://www.diputados.gob.mx/LeyesBiblio/pdf/257.pdf)

8 To date INALI has carried out linguistic research and published a national catalogue of languages; it has produced numerous works in and on indigenous languages, including multiple translations of the Mexican constitution and other governmental documents; it has created norms for the preparation and licensing of translators and interpreters; and it has provided limited legal advise in individual cases of linguistic discrimination.

9 http://www.enlace.sep.gob.mx

10 http://www.ceneval.edu.mx 
Spanish. Since that moment, Hispanization has been an "unquestionable imperative" in indigenous education (Flores Farfán 1999:37). Mexican bilingual education grew after its creation and continues to expand to this day, contributing to the massive replacement of indigenous languages with Spanish. And, paradoxically, only a portion of Nahuatl-speaking communities have access to this form of 'bilingual' education and many are subject to an entirely Spanish school program. Elementary education is highly centralized, with materials and curricula produced almost exclusively by the federal Secretary of Education and are entirely based on the Spanish model of language learning. Individual teachers do not participate in innovating curriculum development, but are trained as technicians who implement ready-made materials. Bilingual teachers are trained, for the most part, in Spanish, and are thus unable either to teach in a native language, or to explore and apply a native perspective and concepts in the educational process. They are entirely unprepared to creatively use language terminology developed from inside a native language, without merely calquing Spanish concepts. Their preparation process does not offer them solid linguistic and philological grounds either. Textbooks are only produced for a limited number of language varieties, whereas bilingual teachers are routinely given jobs in communities that speak variants and even languages different from their own. It is also not uncommon for children to be encouraged to stop speaking their native language at school; they are discriminated against by Spanish-speaking schoolmates with the consent of teachers, who even advise parents to speak only Spanish to their children.

The current situation of native-speaking children in Mexico and their Spanish-language proficiency closely parallels that of Native American children in the United States, who are likely to be stigmatized as "limited English proficient." In some communities in the United States this challenge has motivated bold new strategies for indigenous schooling that emphasize immersion in the heritage language and community-based planning (McCarty 2003:147-158). Immersion schools started to develop in the 1980s, based on the principle that English as the dominant language should only be taught in school as a foreign language (Hinton 2011:298). This approach has been virtually unknown and absent in Mexico. Although nidos de lengua 'language nests' were established in Mexico, especially Oaxaca, beginning in 2008, with at least ten language nests in existence by late 2009, serving the Mixtec, Zapotec, and Cuicatec languages (Meyer and Soberanes Bojórquez 2009), their small scale and limited distribution cannot meet growing challenges. Indeed, an immersion program could be implemented in Nahuatl-speaking communities, using the model of pre-school language nests, in which the fluent speaking grandparent generation, often the last fully proficient generation of native speakers, would take care of young children using only the indigenous language.

While adverse language attitudes prevail at the community level, many covert forms of discrimination take place when the students enter junior high, high school, and college. During the presidency of Vicente Fox (2000-2006) the federal government abandoned an attempt considered earlier to create spaces for indigenous education in the public universities. Instead, a new system of intercultural universities was established. Nevertheless, most of these underfunded institutions do no more than offer traditional careers in Spanish to a largely 
indigenous student population. Curiously absent at all Mexican universities, including the Universidad Nacional Autónoma de México with its flagship program, "Mexico Nación Multicultural", ${ }^{11}$ is the basic mode of activity with which these institutions could trigger a national movement of indigenous linguistic and cultural revitalization: a large-scale practice of curriculum development, teaching, and research done entirely within an indigenous language.

\section{Our methodological proposal for research, teaching and revitalization}

For almost five hundred years now, knowledge related to all aspects of indigenous cultures has been produced by Western scholars who extract data using Western methodology from human and non-human indigenous sources, interpret the data using Western theoretical models, and publish the results of their work in non-indigenous languages. Unless we start from the premises that indigenous language and culture are incapable of generating unique methodology and theory and that indigenous people are incapable of conducting research, the only explanation for the exclusion of indigenous people and their perspective from Western academia must be ideological. We have begun a long-term experiment designed to see if research could be conducted in a different way; conducted by indigenous people on and from within their own language and culture, and in collaboration with, rather than subordinated to Western researchers. In essence we are proposing a major change in studying Nahua language and culture, educating indigenous people in Mexico and undertaking collaborative language revitalization activities.

\subsection{Research methodology}

Instituto de Docencia e Investigación Etnológica de Zacatecas (IDIEZ) and the University of Warsaw's Faculty of "Artes Liberales" have been working with Nahua immigrants from the Huasteca region who are studying at the Universidad Autónoma de Zacatecas and more recently also with native speakers from Puebla and Tlaxcala. Offering an alternative to the general function of the Mexican university as the last step in the educational process of Hispanicization, these students are provided with different opportunities, which allow them to continue practicing and developing their language and culture; parallel to the careers they study at the university, they are trained to teach Nahuatl and they actively collaborate with international academics in many types of research projects. Traditionally, Western ethnographic researchers have incorporated native speakers of indigenous languages into their work as informants whose role in the research process is limited to the passive transfer of raw linguistic data. A firm boundary is usually drawn between the informant (conceived of as a possessor of native cultural knowledge) and the anthropologist (the only participant capable of understanding and interpreting this knowledge at an academic level). We deconstruct this boundary by assigning active roles to students and researchers who are members of the communities under investigation. These roles embrace field research, the analysis of ethnolinguistic data, ethnohistorical and linguistic studies

11 Mexico: Multicultural Nation. http://www.nacionmulticultural.unam.mx 
as well as teaching activities. Thus, in our approach we do not "read over the shoulders" of the natives (Geertz 1973:452), but strive to combine inside and outside perspectives in ways that are new to existing scholarship.

Indigenous students in collaboration with members of native communities and nonindigenous researchers carry out fieldwork, transcribe, translate and analyze materials they have collected and use them both in their individual research activities and in broader team projects. These include a European Research Council funded project, "Europe and America in Contact," carried out by the University of Warsaw, IDIEZ, and the University of Seville, focusing on longterm cross-cultural transfer and contact-induced change in Nahuatl, and Stephanie Wood's NEH funded project, "An Online Nahuatl Lexical Database: Bridging Past, Present, and Future Speakers." During our summer courses for non-native speakers we began requiring students to bring a research project with them to the course, and then we paired them with our indigenous instructors for an hour per day in order to work on these projects. The students were encouraged to explain to the instructor how they had set up their project and then work on it collaboratively during the summer. The results were unexpected. A high percentage of the students continued to work on their thesis, dissertation, and book projects with their instructor for a long period of time after the course concluded. Some even solicited grants for this purpose. Today, the indigenous members of IDIEZ who are working on their master's theses within the ERC-funded project continue to collaborate with current and former foreign students studying similar topics.

\subsection{Our approach to teaching}

Research is consistent in its findings that high level academic achievement is best attained when children are educated in their native language, and that the worst thing a society can do regarding the preparation of its future thinkers is to immerse students in a second, in this case, dominant language with no linguistic support (Austin and Sallabank 2010:10). And yet, this is how Mexico educates its indigenous population. Children progress through the educational system believing that their language and culture constitute a hindrance to their own personal advancement; but at the same time, they receive none of the second-language assistance that would allow them to fully participate in the Spanish language curriculum. Add to this the fact that Mexican culture does not value or teach critical and creative thinking in general, and the result is marginal participation of indigenous people in all levels and areas of academic life.

In response to this, IDIEZ has created a monolingual space, where indigenous students at the Universidad Autónoma de Zacatecas can continue to use their language and practice their culture, through participation in the teaching, research, and revitalization projects we design and implement. An indigenous college student has resigned him or herself to the fact that their language has no place in academia, so the first thing this student must do after entering IDIEZ is to start thinking conceptually in their language. This is achieved when the student begins to participate in the production of our monolingual dictionary of Modern Huastecan Nahuatl. Crafting definitions for words is a standard reasoning exercise used in many educational 
curricula for native-speakers. Our students have never done this, and much less in their own language. Many experience headaches during the first few weeks, and all resort to a very interesting strategy for pondering the content and wording of the definitions: instead of using abstract reasoning, they transport themselves mentally back into their village and imagine how a concept might be verbalized among real people. To date, students at IDIEZ have produced monolingual definitions and example sentences for almost nine thousand headwords.

The Mexican educational system treats indigenous civilization as a relic of the past and only includes superficial aspects of it in the national curriculum. Many Nahuatl-speaking students are not even aware of the fact that their ancestors produced the largest corpus of indigenous language writing in America. We believe that a person cannot be considered well educated, or even have a sense of historical identity, without studying his or her cultural legacy. Some protest, affirming that Classical Nahuatl is a dead language that cannot be understood by today's speakers of modern dialects. In January of 2014 in our Nahuatl Language and Codex Institute, held in the city of Cholula, we brought together foreign and Mexican researchers and students and a group of Nahuatl-speaking high school students from the town of Zoyatla, Puebla, and other native speakers from the region. The indigenous participants had gone through their basic education entirely in Spanish, and had never read anything written in their own language. For two weeks, we transcribed, translated, analyzed, and discussed together a number of colonial manuscripts, written in Nahuatl, the earliest being a mid-sixteenth century manuscript with pictorial and glyphic components from Chalco Amaquemecan, followed by seventeenth- and eighteenth-century mundane documents from the Cholula region. The students had no trouble reading and understanding the manuscripts. One of the sessions was held in Zoyatla and was attended both by school children and adult members of the community. The course also included the reading of colonial pictorial manuscripts and instruction in modern Nahuatl.

The study of the past is important for practical reasons. We have been able to identify vocabulary, concepts, and even grammatical structures from colonial Nahuatl that have fallen out of use and that can be reintroduced into today's variants. For example, we were able to identify the word copactli 'soft palate' from Molina's (2001 [1571]) dictionary and incorporate it into our monolingual dictionary definitions of phonological processes. But the study of the past is also more generally important because it makes indigenous students aware of the fundamental relationship of continuity between them and their ancestors, effectively empowering them to participate more critically and productively in their daily lives. The Nahuas must have access to their past if they are to actively promote the survival and development of their culture.

Our next step in developing and institutionalizing our strategies will be to found a monolingual master's degree program in Nahuatl Studies at the Universidad Autónoma de Zacatecas in Mexico, with international support. We expect the majority of the students to be native speaking bilingual elementary education teachers, who will gain the background in the theory and methodology of second language instruction and learning processes that they will need in order to design and implement teaching and revitalization activities in their communities. However, we also plan to include non-indigenous academics from Mexico and other countries 
who wish to teach, conduct research, and participate in revitalization projects.

\subsection{Creating reference works and terminology}

We have started the preparation of monolingual reference materials with the monolingual dictionary of Modern Huastecan Nahuatl, but we are also preparing a monolingual grammar, a thesaurus, and research works (theses) written entirely in Nahuatl by indigenous students themselves. We believe that monolingual reference works constitute a key component for the infrastructure needed for any kind of research and teaching directly related to an indigenous language and culture. This implies the creation of a huge amount of new technical and theoretical vocabulary. No monolingual grammatical terminology for Nahuatl existed before we began working on our dictionary. But we did not want to simply generate translations of the concepts used to describe European languages. Rather we produce neologisms from within Nahuatl. An example is our word for the lexical category which roughly corresponds to "noun." A Nahuatl noun does not resemble its counterpart in English or Spanish. It is not simply a label for a person, place, or thing. The simplest form of a Nahuatl noun has three morphemes: a subject prefix, a root, and a number suffix for non-possessed nouns. For example:

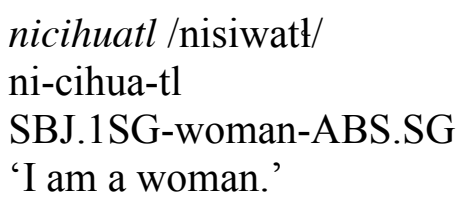

So, a Nahuatl noun is actually a complete sentence, the function of which is to provide a subject with a name. Tlatocaxtia, in Modern Huastecan Nahuatl means 'to provide somebody or something with a name'. This is composed of tla-, the non-specific non-human object; tocax, a combining form of tocaitl, "name"; - $t$, a verbing suffix, meaning "to have [the incorporated noun]; and the causative suffix, - $a$. Tlatocaxtia, literally 'to cause something to have a name', can then be transformed into an active-action noun by adding the suffix -liztli, producing tlatocaxtiliztli 'the act or process of naming something'. This is the neologism we have created to denote Nahuatl nouns. And we have produced extensive new terminology that permits us to describe the lexical category and the morphological structure of our dictionary's headwords, as well as the phonological processes involved in the articulation of the phonemes and allophones associated with specific letters.

This kind of thinking from within indigenous languages must filter back into secondary and primary education, if indigenous people are to reach their full potential and be able to enrich society with the unique creative perspective their language and culture offer. All of these students will experience first hand the possibilities that emerge in an environment where native speakers of Nahuatl conduct teaching and research from within the unique perspective of their own language and culture, and collaborate with their peers from other cultures. The graduates will be able to take the model back to their home institutions, where they can adapt and develop it 
according to their particular contexts and goals.

\section{$4 \quad$ Standardizing orthography and restoring literacy}

\subsection{Colonial Nahuatl orthography}

The pre-Hispanic tradition of books and glyphic records helped the Nahuas to quickly adopt alphabetic writing and use it prolifically. The rapid development of the Nahua writing tradition was made possible by adapting the orthographic conventions of the Roman alphabet in the 1530s in such major centers as Mexico-Tenochtitlan and Tlatelolco. Friars, who were not only interested in the production of doctrinal materials in native languages, but who also started to teach the local nobility to write in their own language in such important educational centers as the Colegio de Santa Cruz in Tlatelolco, were crucial agents in this process. And once the first generation of indigenous scribes and notaries had begun working, the participation of the Catholic Church in the training process lost importance because qualified indigenous persons in each town took over the task of preparing their successors. By the third quarter of the sixteenth century the number of nobles capable of writing in the new mode was constantly growing. By that time even small towns had a notary associated with the municipal government, while many such figures were busy producing textual records in larger and more populous towns, providing service to the municipal government and individuals (Lockhart 1992:330-331). Beginning in the 1540s various kinds of writing in Nahuatl expanded quickly across the core area of Nahua culture and beyond, and served as a kind of "alphabetic bridge" with other ethnic groups whose written records developed later, but were never so widely acknowledged by Spaniards as documents composed in Nahuatl.

The creation and development of Nahuatl orthography was a task undertaken simultaneously by several friars and their indigenous assistants. It was based on the Spanish values of the Roman alphabet representing similar sounds in Nahuatl, a process which was facilitated by the fact that Spanish had close equivalents for the majority of phonetic elements in the native language. In fact it was Nahuatl that lacked more of the Peninsular sounds. Several phonological features of Nahuatl nevertheless posed a serious challenge, including the glottal stop/fricative and vowel length, which were usually left unmarked, as well as voiceless glottal fricatives. Other non-compatible elements were coped with quite well. The native sounds [tt] and [ts] were rendered as digraphs, while the double $l$, lacking in Spanish then, was modeled on the Latin $l l$. Early orthographers also became aware of the fact that in Nahuatl voiced consonants are voiceless at the end of a syllable, so they changed prevocalic hu- [w] to -uh in syllable-final positions, doing the same with -uc and -cuh for the sound $\left[\mathrm{k}^{\mathrm{w}}\right]$. This system, first developed by the ecclesiastics, was immediately reshaped by native scribes and authors, whose primary concern - differing from the European priority given to standardized, conventional forms - was to reproduce not only orality, but also phonetic features that could change as a result of phonetic interaction with the sounds of neighboring words. Unlike for Spaniards, the word as such was 
neither an important nor easily recognizable entity for the Nahuas, who tended to record sounds in an ongoing string of letters (Lockhart 1992:336-339). Thus, an innovation introduced by indigenous writers was to use the alphabet to reproduce pronunciation, not established spellings for every word, while the rendering of a given word or syntactic unit could change because of neighboring words. This native adaptation and the relative flexibility in the use of orthographic conventions does not disappear over time and never gives way to full standardization.

Although there were further attempts at standardization undertaken by such Europeans as Horacio Carochi, who published his outstanding Gramática de la Lengua Mexicana in $1645^{12}$, these had little impact on the traditions of literacy and ways of writing in native communities. As we move toward Stage 3 of contact-induced change according to Lockhart (cf. section 2.1), in the late seventeenth and through the eighteenth centuries, the orthography in indigenous writing became more regionalized, reflecting local, unstandardized variants of spelling (Lockhart 1991:122-134; Pizzigoni 2007:35-39). Local and regional differences thus come to surface in the written language, and, to a certain degree, in the native handling of orthography. Thus, we have for example $\mathrm{z}$ for tz, like tetazin instead of tetatzin and hespiritu instead of espiritu in a 1739 will from Ixtenco, Tlaxcala, or quimotillisquen for quimoittilizqueh in a 1766 will from the same locality. Further destandardization of Nahuatl orthography toward the end of the colonial period is best explained not as a result of phonological evolution; rather, it should be attributed to the decreasing involvement of the native nobility who spoke a more standardized Nahuatl than the commoners and gradually switched to Spanish. The more localized Nahuatl spoken by the lowerranking people became more dominant in written texts (Lockhart 1991:134).

\subsection{Modern standardized orthography of Nahuatl: Our implementation}

Revitalization will not be successful unless Nahuatl literacy is developed and extended through the general population, both as a means of expression and communication and as a vehicle for accessing the cultural legacy available in the Classical Nahuatl corpus. And this will only be possible with the help of a standardized orthography, which encompasses all variants across space and time. Unfortunately, at this time there are multiple orthographies in use and none, with one exception, have been standardized through the publication of rigorously edited works. Most of these systems are based on two principles. First they rest on the mistaken premise that the purpose of an alphabet is to represent phonemes and/or allophones. ${ }^{13}$ Second, they seek to distance themselves from Spanish orthography, substituting s [s] for Spanish c and z, and substituting $\mathrm{k}[\mathrm{k}]$ for Spanish $\mathrm{c}$ and qu, for example. Both of these foundations have disastrous consequences. On the one hand, we know that pronunciation differs greatly between variants,

12 Carochi proposed the use of a system of diacritics to represent vocalic length and the glottal stop; nevertheless, and as a rule, indigenous writers never considered the representation of these two language characteristics important.

13 As Lüpke correctly pointed out, "It is widely assumed by linguists that the basis of the ideal orthography is phonemic. If this was the case, the main difference between a phonemic transcription and an orthography would be the inventory of symbols used" (2011:331). 
and often between villages in a single region, so it is obvious that an alphabet based on the representation of sounds will not facilitate communication. On the other hand, the presence of non-Spanish elements, the inclusion of which in the orthographies is justified by most people as a political statement, hampers reading by young children, who must learn separate spelling systems for Spanish and Nahuatl, and also makes it difficult to read texts in Classical Nahuatl, which are written in Spanish orthography.

There is another, less widely used tendency, which can be termed "enriched traditional orthography," and is based on colonial Nahuatl writing. The Asociación de Escritores Indígenas, A.C., ${ }^{14}$ uses Alonso de Molina's mid-sixteenth century dictionary (Molina 2001 [1571]) as its model. And the ACK traditional enriched orthography, named after the key researchers who have contributed to its standardization, i.e., Richard J. Andrews, R. Joe Campbell, and Frances Karttunen (Andrews 1975; Campbell and Karttunen 1989; Karttunen 1983), is based on Horacio Carochi's mid-seventeenth century grammar (Carochi 2001 [1645]).

We have chosen to use the ACK system in our project to standardize Nahuatl orthography across all modern varieties and colonial texts for three reasons. First, it is based on colonial orthography, with minor modifications: the glottal aspiration [h], which was seldom represented in colonial writing, is written as h; vowel length, again seldom represented in colonial times, can be signaled with a macron over a long vowel, i.e., $\bar{a}$ [a:]; the colonial ç [s] before [a] and [o] is replaced by z; and the syllable and word final devoiced variants of hu $[\mathrm{w}]$ and $\mathrm{cu}\left[\mathrm{k}^{\mathrm{w}}\right]$ are written $\mathrm{uh}[\mathrm{M}, \mathrm{h}]$ and $\mathrm{uc}\left[\mathrm{k}^{\mathrm{w}}, \mathrm{h}\right]$. This is all important for making colonial texts accessible to modern readers. Second, rather than representing sounds, it emphasizes the morphology that is shared by all varieties of Nahuatl. An orthography that makes this characteristic of the language apparent to its readers will have two benefits: it will facilitate interdialectal communication and it will permit both native and non-native students to intuitively and conceptually understand how the language works. Third, the ACK system is, in fact, the only orthography of Nahuatl that has ever been rigorously implemented in a large corpus of the language.

We plan to carry out a universal standardization of Nahuatl by applying the ACK system to all modern variants of Nahuatl and to a large number of colonial texts, and publish the resulting works through our monolingual editorial series. What will this entail? Standardizing the orthography of Nahuatl is a complicated task, which is not understood by the two Mexican institutions that will be instrumental in divulging it to the general population, the aforementioned INALI and the Federal Secretary of Education's Department of Indigenous Educations (DGEI), ${ }^{15}$ both of which advocate sound-based orthographies. The DGEI recently announced that it had achieved a "consensus" in indigenous groups and communities regarding the letters to be used in the Nahuatl alphabet. And INALI has adopted a populist strategy consisting in having representatives of indigenous groups and communities vote on which letters to use, but insisting

14 Some of the members of the Asociación de Escritores Indígenas, A.C. include Librado Silva, Francisco Morales and Natalio Hernández, all of which are participants in the Seminario de Cultura Náhuatl that Miguel León Portilla has directed for over fifty years at the National Autonomous University of Mexico.

15 Dirección General de Educación Indígena. 
that the chosen system is only a suggestion, and that everyone should be able to spell however they want. Both institutions believe that they have now completed the standardization of Nahuatl orthography.

The process is actually much more complex that this. We began with an understanding of how the creators of the ACK system used a set of letters to write a large corpus of words from colonial Nahuatl. However, our initial task was to employ this system in order to write a monolingual dictionary of Modern Huastecan Nahuatl, that would include entries with a headword, grammatical and verb class categories, Molina's prefix clues, definitions, example sentences, morphological analysis as well as derivations, including preterite, causative, and applicative forms for verbs; plural and possessive for nouns; as well as impersonal, reduplicative, and combining forms for verbs, nouns, and relationals. One thing is to decide how to spell a headword. Another thing is to make and codify decisions regarding how to spell all of its variants and conjugations, identify morphemes, and represent them transparently without departing so far from the letter-sound relationship that a native speaker will not be able to associate the word with its referent.

As an example of these kinds of decisions, we can examine the following letters of the ACK Nahuatl alphabet with their corresponding phonemes: $\mathrm{h}[\mathrm{h}], \mathrm{c} / \mathrm{qu}[\mathrm{k}], \mathrm{t}[\mathrm{t}], \mathrm{cu}\left[\mathrm{k}^{\mathrm{w}}\right], \mathrm{hu}[\mathrm{w}]$, and $\mathrm{n}[\mathrm{n}]$. In a syllable initial position, each letter represents its assigned phoneme:

$\begin{array}{llll}\mathrm{h} & \text { ehecatl } & / \text { ehekat// } & \text { "wind" } \\ \mathrm{c} / \mathrm{qu} & \text { caqui } & / \mathrm{kaki} / & \text { "to hear something" } \\ \mathrm{t} & \text { mati } & / \mathrm{mati} / & \text { "to know something" } \\ \mathrm{cu} & \text { tzacua } & / \mathrm{tsak} \text { a/ } & \text { "to close something" } \\ \mathrm{hu} & \text { cahua } & / \mathrm{kawa} / & \text { "to leave something" } \\ \mathrm{n} & \text { niman } & / \text { nimana/ } & \text { "then, immediately" }\end{array}$

However, in some syllable-final, word-internal positions, the first five sounds can undergo changes and will all be pronounced as the voiceless glottal fricative $[\mathrm{h}]$.

$\mathrm{h}$ is pronounced with more force:

pahtli /pahtli/ "medicine"

$\mathrm{c} / \mathrm{qu}$ is softened before $/ \mathrm{k} /$ :

cacqui /kahki/, "to hear something" (preterite)

$\mathrm{t}$ is softened before $/ \mathrm{t} /$ :

mattoc /mahtok/ "to know something" (present perfect)

$\mathrm{cu}$ is devoiced and loses its rounding before [k], and is respelled uc: ${ }^{16}$

tzaucqui /tsahki/ "to close" (preterite)

$\mathrm{hu}$ is also devoiced and loses its rounding before [k], and is respelled uh: ${ }^{17}$

16 Spelling convention adopted in the sixteenth century. 


$$
\text { cauhqui /kahki/ "to leave something (preterite)" }
$$

And in the word-final position, $\mathrm{h}$, and hu are pronounced as a very soft version of the voiceless glottal fricative $[\mathrm{h}]$, and $\mathrm{n}$ is devoiced [n], producing a sound almost indistinguishable from the voiceless glottal fricative:

$\mathrm{h}$ is softened:

maltih /mattih/ "to bathe" (preterite)

uh is devoiced and loses is rounding, and is respelled uh:

$\mathrm{n}$ is devoiced

$$
\text { noconeuh /nokoneh/ "my child" }
$$

xiyacan / / Jijakan/ "Leave (you, pl.)!"

In the preceding examples we have eight distinct elements that can represent or approximate a single sound. We spell them in a way that allows the reader to identify morphemes and their characteristics: pah- is the morpheme for "medicine"; cac-, mat-, tzauc-, cauh- and maltih- are reduced stems of the verbs caqui, mati, tzacua, cahua and maltia; ${ }^{18}$ the -uh of coneuh is the singular nominal possessive suffix, and the $-\mathrm{n}$ of xiyacan is the plural marker of the imperative.

Sound-based orthographic systems, such as those used by the INALI and the DGEI, write all of these sounds, sometimes including even the devoiced syllable- or word-final 1 [1], using the letter $\mathrm{j}$, because it represents the voiceless glottal fricative in Spanish. The word final $\mathrm{h}$, uh and $\mathrm{n}$ are frequently not represented at all.

"wind"

"medicine"

"to hear"

"heard"

"to know"

"has known"

"to close"

"closed"

"to leave"

"left"

"bathed"

"my child"

"Leave!"

"to tell somebody"

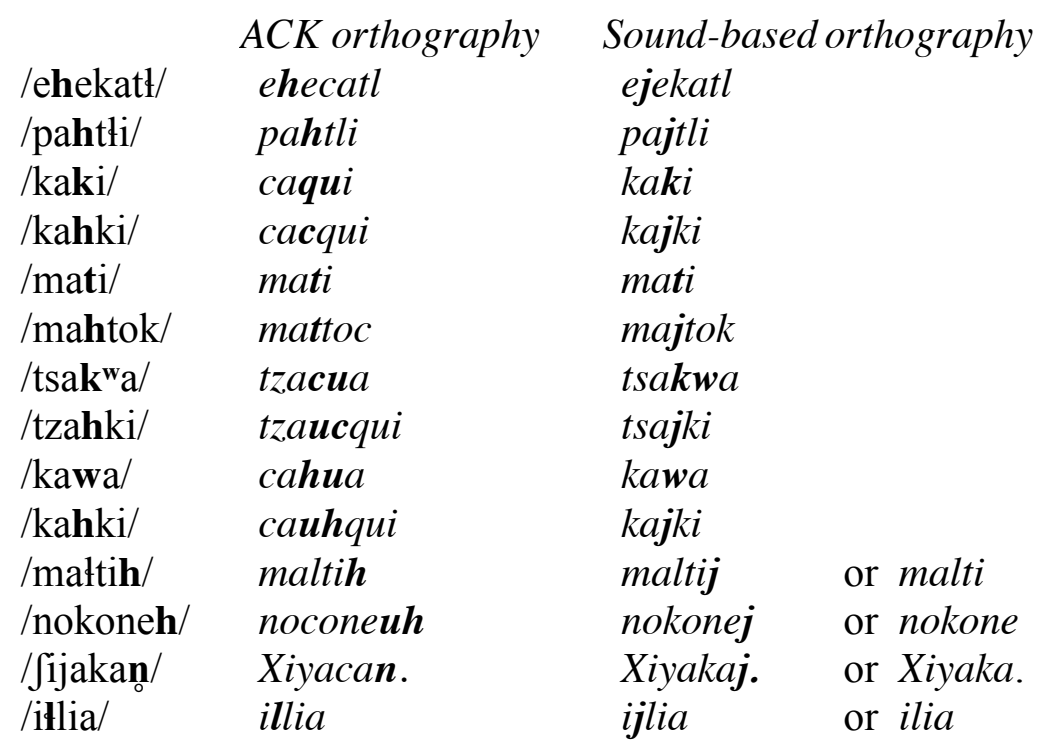

17 Spelling convention adopted in the sixteenth century.

18 The final -a of maltia was historically -ta. When the verb stem is reduced, the t reappears and softens to h. 
There is nothing more conducive to revitalization than promoting communication. A standardized orthography is key to this task, and it should be crafted with this in mind. It should highlight the aspects of a language shared by all of its varieties in order to promote contact between their speakers. In the case of Nahuatl, this aspect is its morphology. It should allow people to read, write about and discuss together their cultural legacy. And it should, if possible, serve as a transparent window into the structure of the language. The ACK Nahuatl orthography carries out these functions, and we will use it to publish and circulate works from all varieties of modern Nahuatl and colonial Nahuatl, thus promoting a new growth in literacy and contributing to the revitalization of the language.

\subsection{Importance of Nahua literacy}

As has already been emphasized, within the first two decades after the Spanish conquest the Nahuas started to use alphabetic writing for their own purposes, producing a corpus of literary and mundane texts that in terms of its size and heterogeneity remains unparalleled in native America. In many places this prolific tradition continued until the nineteenth century. Production tapered off after Mexican Independence and was not resumed in force until the 1970s. At this time we begin to see works of literature in poetry, narrative, theatre, and essay published in Nahuatl. Many of these writers, such as Natalio Hernández, emerged from the ranks of teachers who had become disillusioned with the national system of education. In spite of these initiatives, the restoration of Nahua literacy and its adaptation to modern genres, themes and media encounters serious obstacles today, above all, the lack of consensus regarding the orthography and the false propaganda regarding the mutual incomprehensibility of modern "dialects" of Nahuatl.

It is often emphasized, even in scholarly circles, that alphabetic writing is not an inherent element of tradition or practice in indigenous communities, but something imposed for historical and colonial reasons, an ethnocentric "reductionism" (Flores Farfán 2009:125). Indeed, at no time during this period of almost five hundred years has literacy or the practice of reading and producing literary works been widespread among the Nahua population; however, ethnohistorical research clearly shows that writing was an important and efficient tool not only in the hands of the indigenous nobility, but also among members of the middle and even lower classes, who used it for legal purposes. Besides, it permitted and triggered the conservation and perpetuation of historical tradition and collective memory, as attested by the widespread tradition of community-based annals and so-called "primordial titles" in the middle and late colonial period. Since its very beginning, alphabetic writing in Nahuatl was closely linked to indigenous orality, providing means to record oral genres in ways that were not available in pre-conquest glyphic writing. The tradition and its corpus is a fact, and we believe that unless it is reactivated, spread and developed, no attempt at revitalization will be successful.

Thus, even if we accept the view that the requirement of literacy stems from a bias on the part of the dominant/Western cultures of the world, there should be no doubt that "in order to 
function in a globalized world one does need to be literate" (Grenoble and Whaley 2006:135). Today native communities should not be conceived of as traditional and isolated enclaves, because younger generations are active participants in "electronic culture" and media. Therefore, we should not consider that recipients of writing are limited to teachers and schoolchildren; rather, important target groups for indigenous writing are teenagers and young adults actively communicating with each other via the internet, and especially through social portals which form a major space for the "popular culture" of writing today. Each of our native-speaking students from Zoyatla, all high school teenagers, mentioned independently and with no elicitation from us, that the primary reason for their participation in the course was their desire to learn to write in Nahuatl. Thus, the introduction and propagation of writing should be oriented toward the development of functional communicative competence, but it should also take into account the sociolinguistic and cultural factors of a given community, as well as the need to gain local acceptance and support for this kind of initiative (Flores Farfán 2009:127).

Therefore local attempts to (re)create literary culture should be stimulated and fully supported by academic circles and within revitalization projects carried out in collaboration with native communities. This support must entail instruction in orthography, training in reading older and modern Nahuatl texts, encouraging critical reading and creative writing, providing skills needed for producing written/literary texts, as well as furnishing technical and editorial opportunities for publishing works produced by members of a specific community. Crucial for this enterprise is the unification of its orthography in close relationship to the older tradition of writing in Nahuatl. The standardized orthography we are implementing in our research, teaching and revitalization activities not only permits written communication across variants, but also emphasizes the continuity between older and modern Nahuatl language and culture. Therefore, we encourage indigenous people to create monolingual spaces in their communities and educational institutions in order to read and discuss works that their ancestors and contemporaries have written, as well as to create works of their own.

To carry out this goal we have launched a monolingual Totlahtol series, published through the University of Warsaw and IDIEZ in collaboration with institutions in Mexico and the USA, that will include older and contemporary written works, as well as reference materials, such as the monolingual dictionary of Modern Huastecan Nahuatl, in standardized orthography. Refugio Nava's book of children's literature, Malintzin itlahtol (2013), written in Tlaxcalan Nahuatl, and Gustavo Zapoteco Sideño's volume of poetry, Chalchuhuicozcatl (2014), composed in Nahuatl from Guerrero, are the first works published in this series. Publishing historical sources and making them available not only for scholars but also for native speakers will be crucial for restoring and strengthening the historical identity of the Nahuas and for helping to raise the status of their language. All of these publications are prepared in paper versions-which we consider important for the prestige of written language, both in the eyes of speakers and their communities and in the academic world - and in open-access electronic publications assuring their unrestricted distribution among native speakers of all varieties, teachers, students, and scholars. 


\section{$5 \quad$ Communication across barriers and international support}

The success of Nahuatl revitalization efforts will depend to a large degree on the ability of native speakers from different regions of Mexico to communicate and collaborate with each other in the planning and implementation of projects for the development of their language and culture. The lack of contact between different isolated Nahua communities makes them even more vulnerable to rapid language shift (Flores Farfán 2002:229). However, international collaboration is also very much needed if indigenous people are to overcome the strong tendency toward Hispanization in Mexican society. Until recently, geographic distance and the differences between linguistic variants constituted what was considered an insurmountable barrier to the possibility of interregional communication. However, in December of 2011, as part of a research project funded by the US National Endowment for the Humanities, ${ }^{19}$ IDIEZ brought together twenty native speakers representing approximately ten variants of Nahuatl for a five-day workshop in Zacatecas. A second Interdialectal Encounter of Nahuatl, financed by the Mexican National Commision for the Development of Indigenous Peoples (CDI) ${ }^{20}$ and organized jointly by IDIEZ and the University of Warsaw, was held over the weekend of January 18 and 19 of 2014 in the city of Cholula with the participation of sixty native speakers and thirteen non-native speakers. Both events were recorded and broadcast by "XECARH The Voice of the Hñahñu People," a radio station affiliated with the CDI.

In our two Interdialectal Encounters, the topics of discussion were reviewed and ratified or modified by the indigenous participants at the beginning of each event, and all discussions were held monolingually in Nahuatl. As a rule, native speakers of indigenous languages communicate with each other in Spanish outside of their community. And if they must use their language in a public situation, they will immediately translate what they have said into Spanish. Not surprisingly, this behavior was replicated by some of the indigenous participants at the beginning of each Interdialectal Encounter, probably reinforced by the belief that speakers of different varieties of Nahuatl would not be able to understand each other. In fact, before the 2011 event it is probable that no one really knew if interdialectal communication would be possible. In both events, however, it immediately became apparent that a high enough degree of intelligibility existed to permit fluid and animated monolingual discussions on a diverse array of topics, including identity, revitalization, rituals and local festivals, ways of greeting, education, immigration, grammatical terminology, linguistic policy, migration, intergenerational language transmission, gender issues and interculturality. Perhaps most important is the shift in attitude that occurs among the participants as the discussions progress and they are able to experience interdialectal communication for themselves. They unanimously agreed that more interdialectal

19 The project, An Online Nahuatl Lexical Database: Bridging Past, Present, and Future Speakers, was directed by the University of Oregon's Dr. Stephanie Wood from 2009 to 2012.

http://whp.uoregon.edu/dictionaries/nahuatl

20 www.cdi.gob.mx 
encounters, and more diverse modalities of these activities, such as a research conference in Nahuatl, should be planned on a regular basis. At the end of the 2014 event, we opened a Facebook site and monitor subscription and participation in order to assure monolingual communication in Nahuatl.

We have also started to spearhead the formation of an international consortium of institutions of higher education to foment the teaching, research, and revitalization of Nahuatl language and culture. By promoting these strategies of inter-institutional cooperation, we make Nahuatl instruction available to anyone in the world who wishes it, acknowledging the importance of neo-speakers for research and revitalization projects. Indigenous students actively participate as researchers in long-term team projects carried out by the University of Warsaw and IDIEZ and financed by the European Research Council, the Foundation for Polish Science and the Polish Ministry of Science and Higher Education (National Programme for the Development of the Humanities); the long-standing colonial Nahuatl teaching program carried out in Warsaw since 2000, was enriched in 2012 by a course in modern Nahuatl taught by a native speaker, making it the only permanent full academic year Nahuatl program of its kind. We want to create even more opportunities for Western and indigenous researchers to participate in these kinds of collaborative projects. The aforementioned Cholula Winter 2014 Nahuatl and Codex Institute was a recent successful experiment of this kind that will now be continued on a yearly basis. Yet another complementary endeavor is our revitalization website dealing with three endangered languages: Nahuatl in Mexico and Lemko and Wymysiöeryś in Poland. ${ }^{21}$ Its three domains of research, culture (including literature) and education, describe, document, and recreate the universe of each of the endangered languages. And they are all presented in monolingual interfaces in each of the three endangered languages, plus English, Polish, and Spanish. The website has been designed, on the one hand, as a space available for writers in Nahuatl, Lemko, and Wymysiöeryś to publish their works, and on the other hand, as a resource repository for scholars and students working on those languages and their communities. Its target user groups include speakers of endangered languages, students, and scholars.

It is probably safe to say that there has never been a successful indigenous language revitalization project in Mexico. Racism is a structural aspect of Mexican society that is not recognized and addressed in the public forum: unhindered by criticism, it generates pervasive discrimination against indigenous people that cannot be countered by limited and isolated revitalization efforts. We believe that an international consortium of committed institutions and individuals can provide the independent funding, experience, creative theories and strategies, and prestige that may foster language revitalization projects and assure their success.

\section{Conclusions and proposals for the future}

Our proposal for the revitalization of Nahuatl requires fostering collaboration across academic, social, and ideological boundaries, as well as efficiently combining grassroots and top- 
down approaches. It is necessary to bridge the gap between theory and practice in revitalization, i.e., between the study and planning of revitalization in academic circles and the implementation of concrete programs, be they community-based, educational, or the direct result of governmental language policy. The urgent need to combine different levels of activities in the revitalization of native languages of Latin America, including the pedagogical, public, and sociolinguistic spheres, has already been emphasized (Zimmermann 2011:34-36), but it is high time to put it into practice.

A fundamental part of our approach involves compiling extensive documentation of both a historical (archival texts) and an ethnolinguistic (field materials) nature. In our team projects we study and use these resources to create dictionaries, grammars, and pedagogical materials, adapting the products of linguistic research for use in revitalization. Lexical and structural data from historical documentation can be reintroduced into modern language in order to enrich the linguistic tools available to native speakers. We also aim to strengthen the historical and cultural identity of native speakers by facilitating their access to the texts written by their ancestors through the colonial era and making research results more available to native researchers and other members of speech communities. An important objective of our research is to document and analyze the degree of continuity between older and modern Nahuatl as well as reconstruct the last five centuries of evolution of Nahua language and culture. Disseminating this knowledge may help to construct positive language attitudes among native speakers and in Mexican society as a whole.

Education has an important place in our activities and is linked to our research and publication projects. It is extremely necessary to stimulate the teaching of Nahuatl at all academic levels; researchers and native speakers should collaborate in creating innovative and efficient resources for instruction. Therefore, we plan to establish a monolingual university program grounded in international collaboration, and strive for efficient collaboration with state educational institutions in order to extend the presence of native languages in primary and secondary education and improve teaching methodology. Crucial to the fortification and development of Nahuatl education and literacy is the implementation of the standardized orthography and the preservation of the richness of varietal differences.

Our approach involves direct collaboration with members of the language communities we are studying and working to revitalize. A fundamental aspect of our methodology involves transforming the traditional academic division between the ethnographer and the language community under study: native speakers can be trained to do research and they can collaborate on projects with non-indigenous researchers. This will not only empower native speakers, but will enrich ethnographic research with the addition of the insider perspective it has always lacked. Thus, native speakers work with us as students and researchers, not informants. They are provided with training to stimulate their successful and active involvement in educational, social, and political tasks essential for guaranteeing the survival and development of their language and culture. Native-speakers are also encouraged to creatively develop and extend the use of their language into more and more sectors of modern life, especially through the creation and 
expansion of spaces for monolingual language practice.

All these goals are closely linked to and depend on the construction of positive language attitudes. It is indispensable for building the self-confidence of native speakers, strengthening their historical and cultural identity, and enhancing their professional performance. An essential aspect of this endeavor is the revival and extension of the culture of Nahua literacy developed during the colonial period by disseminating standardized orthography and implementing it across varieties; promoting everyday, literary and academic writing in Nahuatl; editing and publishing contemporary and older texts in standardized orthography, circulating them and encouraging people to read and discuss them. The isolation of Nahua communities and the lack of interregional communication can be overcome by holding interdialectal encounters, both in person and using videoconference technology, and by promoting monolingual communication in indigenous languages in the social media.

Finally, we need to tear down the existing ideological barriers to revitalization by widely disseminating the results of research showing the clear and irrefutable benefits that multilingualism offers to all of society. The revitalization of Nahuatl and other languages should not be seen as an aim in itself. The processes of globalization and homogenization are strengthened by the still pervasive worldwide belief that the establishment of a national language and culture is a fundamental requirement for political stability. However, a society's intellectual and creative potential largely depends on the quantity, the quality, and especially, the diversity of the ideas it can cultivate; these in turn are strongly linked to cultural and linguistic diversity. The most recent results of psycholinguistic research demonstrate a strong correlation between multilingualism and enhanced non-verbal processes. It has been shown that bilingual and multilingual children and adults have expanded cognitive potential, which manifests itself in greater flexibility and capacity for task-solving and in generally higher intellectual and social skills (Bialystok 1999; 2001; Bialystok and Martin 2004; Bialystok and Senman 2004; Bialystok, Craik and Luk 2012; Costa, Hernández and Sebastián-Gallés 2008; Kovács 2009).

These findings seem to be backed up by direct outcomes of revitalization programs: it has been repeatedly shown that children coming out of strong immersion models always match or surpass their counterparts participating in the dominant-language programs, in both classroom performance and standardized testing (Hinton 2001:298-299; McCarty 2003:151-157). Successful language revitalization should therefore be grounded in the advantages of preserving and extending linguistic diversity as well as in the social, cultural, and economic benefits of cross-cultural transfer and communication. In other words, "cultural diversity widens the range of options open to everyone; it is one of the roots of development, understood not simply in terms of economic growth, but also as a means to achieve a more satisfactory intellectual, emotional, moral and spiritual existence" (UNESCO 2002:4).

\section{$7 \quad$ Acknowledgments}

We would like to express our gratitude to Marcin Kilarski for his insightful comments on this 
paper. The research leading to these results has received funding from the European Research Council under the European Union's Seventh Framework Programme (FP7/2007-2013)/ERC grant agreement $\mathrm{n}^{\circ} 312795$.

\section{$8 \quad$ References}

Andrews, J. Richard. 2003. Introduction to Classical Nahuatl, Revised Edition. Norman: University of Oklahoma Press.

Austin, Peter, Julia Sallabank. 2011. Introduction. In Peter Austin and Julia Sallabank, eds., The Cambridge Handbook of Endangered Languages, pp. 1-24. Cambridge: Cambridge University Press.

Bialystok, Ellen. 1999. Cognitive complexity and attentional control in the bilingual mind. Child Development 70:636-644.

Bialystok, Ellen. 2001, Bilingualism in development: Language, literacy, and cognition. Cambridge: Cambridge University Press.

Bialystok, Ellen, Michelle M. Martin. 2004. Attention and inhibition in bilingual children: evidence from the dimensional change card sort task. Developmental Science 7:325-339.

Bialystok, Ellen, Lili Senman. 2004. Executive processes in appearance-reality tasks: the role of inhibition of attention and symbolic representation. Child Development 75:562- 579.

Bialystok, Ellen, Fergus I.M. Craik, Gibi Luk. 2012. Bilingualism: consequences for mind and brain. Trends in Cognitive Sciences 16(4):240-250.

Brenzinger, Matthias. 2007. Language Endangerment Throughout the World. In Matthias Brenzinger, ed., Language Diversity Endangered, pp. ix-xvii. Berlin, New York: Mouton de Gruyter.

Campbell R. Joe, Frances Karttunen. 1989, Foundation Course in Nahuatl Grammar. Missoula: University of Montana.

Canger, Una. 1988, Nahuatl Dialectology: A Survey and Some Suggestions. IJAL 54(1):28-72. Canger, Una. 2001. Mexicanero de la Sierra Madre Occidental. Mexico: El Colegio de México.

Carochi, Horacio. 2001. Grammar of the Mexican Language with an Explanation of its Adverbs (1645), J. Lockhart trans. and ed. UCLA Latin American Studies, vol. 89. Stanford: Stanford University Press.

Costa, Albert, Mireia Hernández, Nuria Sebastián-Gallés. 2008. Bilingualism aids conflict resolution: evidence from the ANT task. Cognition, 106(1):59-86.

Flores Farfán, José Antonio. 1999. Cuatreros somos y toindioma hablamos. Contactos y conflictos entre el náhuatl y el español en el sur de México. Tlalpan, D.F.: CIESAS.

Flores Farfán, Jose Antonio. 2002. The use of multimedia and the arts in language revitalization, maintenance and development. In Barbara Burnaby and Jon Reyhner, eds., Indigenous Languages Across the Community, pp. 225-236. Arizona: Northern Arizona University.

Flores Farfán, José Antonio. 2008. The Hispanization of Modern Nahuatl varieties. In Thomas Stolz, Dik Bakker, and Rosa Salas Palomo, Hispanisation: The impact of Spanish on the lexicon and grammar of the Indigenous Languages of Austronesia and the Americas, pp. 
27-48. Berlin and New York: Mouton de Gruyter.

Flores Farfán, José Antonio. 2009. Variación, ideologías y purismo lingüistico. El caso del mexicano o náhuatl. Mexico: Publicaciones de la Casa Chata.

Geertz, Clifford. 1973. The Interpretation of Cultures. New York: Basic Books.

Grenoble, Lenore A. 2011. Language ecology and endangerment. In Peter Austin and Julia

Sallabank, eds., The Cambridge Handbook of Endangered Languages, pp. 27-44.

Cambridge: Cambridge University Press.

Grenoble, Lenore. A., Lindsay J. Whaley. 2006. Saving Languages: An Introduction to Language Revitalization. Cambridge: Cambridge University Press.

Grinevald, Colette. 2007. Endangered Languages of Mexico and Central America. In Matthias Brenzinger, ed., Language Diversity Endangered, pp. 59-86. Berlin, New York: Mouton de Gruyter.

Grinevald, Colette, Michele Bert. 2011. Speakers and communities In Peter Austin, Julia Sallabank, eds., The Cambridge Handbook of Endangered Languages, pp. 45-65. Cambridge: Cambridge University Press.

Hill, Jane \& Kenneth C. Hill. 1986. Speaking Mexicano: Dynamics of syncretic language in Central Mexico. Tucson, Ariz.: University of Arizona Press.

Hinton, Leanne. 2011. Revitalization of endangered languages. In Peter Austin, Julia Sallabank, eds., The Cambridge Handbook of Endangered Languages, pp. 291-311. Cambridge: Cambridge University Press.

Jensen, Anne. 2008. Hispanisation in Colonial Nahuatl?. In Thomas Stolz, Dik Bakker and Rosa Salas Palomo, eds., Hispanisation: The impact of Spanish on the lexicon and grammar of the Indigenous Languages of Austronesia and the Americas, pp. 3-25. Berlin and New York: Mouton de Gruyter.

Karttunen, Frances. 1992. An Analytical Dictionary of Nahuatl. Norman: University of Oklahoma Press.

Karttunen, Frances, James Lockhart. 1976. Nahuatl in Middle Years: Language contact phenomena in texts of the colonial period. Berkeley: University of California Press.

Kovács, Agnes M. 2009. Early bilingualism enhances mechanisms of false-belief reasoning. Dev Sci 12(1):48-54.

Lewis, M. Paul, Gary F. Simons, and Charles D. Fennig, eds. 2014. Ethnologue: Languages of the World, Seventeenth edition. Dallas, Texas: SIL International. Online version: http://www.ethnologue.com.

Lockhart, James. 1991. Nahuas and Spaniards. Postconquest Central Mexican History and Philology. Stanford: Stanford University Press.

Lockhart, James. 1992. The Nahuas after the Conquest. A Social and Cultural History of the Indians of Central Mexico, Sixteenth Through Eighteenth Centuries. Stanford: Stanford University Press.

Lüpke, Friederike. 2011. Orthography development. In Peter Austin, Julia Sallabank, eds., The Cambridge Handbook of Endangered Languages, pp. 312-336. Cambridge: Cambridge University Press.

McCarty, Teresa. 2003. Revitalising Indigenous Languages in Homogenising Times. 
Comparative Education 39(2):147-163.

Meyer, Lois M., Fernando Soberanes Bojórquez. 2009. El Nido de Lengua. Orientación para sus Guías. Oaxaca: Movimiento Pedagógico.

Molina, fray Alonso de. 2001 [1571]. Vocabulario en lengua castellana y mexicana y mexicana y castellana. Mexico: Porrua.

Nava Nava, Refugio. 2013. Malintzin itlahtol. Totlahtol Series. Warszawa: Faculty of "Artes Liberales", University of Warsaw, Universidad Autónoma de Tlaxcala and Instituto de Docencio e Investigación Etnológica de Zacatecas.

Nesvig, Martin. 2012. Spanish Men, Indigenous Language, and Informal Interpreters in Postcontact Mexico. Ethnohistory 59(4):739-764.

Pizzigoni, Caterina. 2007. Testaments of Toluca. Stanford: Stanford University Press.

Schwaller, John F. 2012. The Expansion of Nahuatl as a Lingua Franca among Priests in Sixteenth-Century Mexico. Ethnohistory 59(4): 675-690.

UNESCO. 2002. Universal Declaration on Cultural Diversity, Cultural Diversity, Series No. 1.

Yannanakis, Yanna. 2012. Introduction: How Did They Talk to One Another? Language Use and Communication in Multilingual New Spain. Ethnohistory 59(4):667-674.

Zapoteco Sideño, Gustavo. 2014. Chalchihuicozcatl. Totlahtol Series. Warszawa: Faculty of "Artes Liberales", University of Warsaw, Universidad Autónoma de Tlaxcala and Instituto de Docencio e Investigación Etnológica de Zacatecas.

Zimmermann, Klaus. 2011. Reflexiones acerca de la revitalización de las lenguas amerindias en México. UniverSOS, 8:9-41. 